\title{
RUPTURED UTERUS IN AZARE, NORTH EASTERN NIGERIA
}

\author{
Dattijo LM $\mathbf{M}^{\mathrm{a}}$, Umar NI', Yusuf $\mathbf{B M}^{\mathrm{b}}$

\begin{abstract}
Department of Obstetrics and Gynaecology, ${ }^{a}$ Abubakar Tafawa Balewa University Teaching Hospital, Bauchi, Nigeria.

${ }^{b}$ Department of Obstetrics and Gynaecology, Federal Medical Centre, Azare, Nigeria
\end{abstract}

Correspondence: Dattijo LM

E-mail:-Lamaran2@yahoo.com

\begin{abstract}
Background:- Ruptured uterus is an obstetric emergency and results in significant maternal and perinatal morbidity and mortality in Nigeria. The objective of the review is to determine the incidence, predisposing factors, maternal and foetal outcome in cases of ruptured uterus.
\end{abstract}

Methods:- A 4-year retrospective review of patients that had uterine rupture between July 2003 and June 2007 in Federal Medical Centre, Azare was carried out. Analysis of available records of the cases of ruptured uterus from the labour room, and theatre during the period under review was done.

Results:- A total of 75 cases of ruptured uterus and 9015 deliveries were recorded in the period under review. The incidence of uterine rupture is 1 in 120 deliveries. The highest incidence of ruptured uterus was found in the grand multiparous women, $46(63 \%)$. Injudicious use of oxytocin was found in more than half of the cases 41(56.2\%). Majority of the rupture (56.3\%) occurred in the lower segment. Thirty-two (45.1\%) had repair and tubal ligation done. Maternal case fatality was $10.7 \%$ while foetal wastage was $86.3 \%$. The commonest complication was anaemia, which occurred in $44 \%$ of the patients.

Conclusion:- The incidence of uterine rupture is very high in Azare. There should be a multi-sectoral collaboration aimed at improving the utilization of medical services by the populace and the organization of health institutions offering obstetric emergency care.

Key Words:- Uterine rupture, Predisposing factors, Management, Outcome, Azare

\section{Introduction}

Ruptured uterus is an obstetric emergency associated with high maternal morbidity and fetal mortality and often indicates poor obstetric care ${ }^{1,2}$. The outcome is worsened in sub-Saharan Africa because of the many delays in treatment. Nigeria with about 2 percent of the world's population contributes about $10 \%$ of the global burden of maternal mortality ${ }^{3}$. The maternal mortality ratio in Nigeria is estimated at 800 maternal deaths per 100 000 live births with wide regional variations ${ }^{2,3}$. The north east region has one of the highest ratios. Rupture of the gravid uterus is a known important contributor to maternal mortality in Nigeria, ${ }^{4,5,6,7}$.

This obstetric hazard is also associated with short term maternal morbidities such as vesico-vaginal fistula, rectovaginal fistula, bladder rupture, foot drop $^{1}$, psychological trauma, anemia and in the long term because of the surgical intervention, the woman may be sterilized which can lead to divorce and loss of economic support

Uterine rupture may occur in an intact or scarred uterus. In an intact uterus, rupture may be due to neglected and poorly managed labours, injudicious use of oxytocics, instrumentation and obstetric maneuvers $^{7,8}$. Symptoms and signs of uterine rupture may include bleeding, abdominal pain, loss of fetal movement, easily palpable fetal parts and deteriorating vital signs.

Once a diagnosis is made, resuscitation is carried out and treatment is either repair or hysterectomy with or without bilateral tubal ligation. Good outcome is dependent on effectiveness of resuscitation and competent surgical management.

Federal Medical Centre Azare was established 10 years ago and serves as a general and specialist Facility for Bauchi state and parts of Yobe and Jigawa states. Many of the patients come from remote areas where transportation is a real challenge. Home delivery is the norm and resort to hospital is usually after failure of attempts at home. The aim of this study is to determine the incidence, aetiology, treatment, complications, and maternal and fetal outcome of ruptured uterus at a suburban referral hospital. 


\section{Materials and Methods}

A retrospective study was carried out in Federal Medical centre, Azare on patients that had rupture of a gravid uterus from July 2003 through to June 2007. During the 4 year study period, there were 9015 deliveries and 75 cases of uterine rupture were recorded. Their case files, labour room and theatre records were reviewed and analyzed. The following definitions were used in this study: Incomplete uterine rupture was defined as the separation of the uterine wall without extension through the entire thickness and its peritoneal cover. Complete uterine rupture was defined when the whole uterine thickness including the peritoneal cover was involved.

Grand multipara was defined as five or more pervious deliveries after 28 completed weeks of gestation. For this study, booked patients implies those patients that had antenatal care in this hospital, booked elsewhere refers private, primary, secondary or other tertiary health facilities. Unbooked refers to patients not in any of these categories. A total of 73 cases were deemed to have sufficient records for analysis, while 2 cases had insufficient documentation. The data were entered and analyzed using the EPI INFO statistical package version 3.5.3(CDCAtlanta).

\section{Results}

There were 9015 deliveries within the 4 year study period and 75 cases of uterine rupture were recorded. This gives on overall incidence of 1 ruptured uterus for every 120 deliveries.

The age of the patients varied between 16 years and 40 years. The highest incidence was in the 31-40 year age group.

Majority of the women were housewives (71\%) and over $76 \%$ had no formal education. None of their husbands is in the professional cadre, businessmen or politicians. Fifty-eight women $(79.5 \%)$ had no antenatal care in the index pregnancy table 1. Predisposing factors identified in this study are shown in table 2. Majority of the patients $(90 \%)$ had complete rupture and the lower segment was the commonest site of the rupture . About $18 \%$ of the patients had hysterectomy(subtotal) while the rest has repair with or without tubal ligation (table 5). Maternal mortality was recorded in 8 cases $(10.7 \%)$ while perinatal mortality was recorded in 63 cases given a case fertility rate of $86.3 \%$.
Table 1 sociodemographic characteristics

\begin{tabular}{lcc} 
Variable & Number & $(\%)$ \\
\hline Age & & 17.8 \\
$\leq 20$ & 13 & 32.9 \\
$21-30$ & 24 & 40.1 \\
$31-40$ & 30 & 4.1 \\
$>40$ & 3 & 8.2 \\
Parity & 6 & 27.4 \\
0 & 20 & 63 \\
$1-4$ & 46 & 76.7 \\
$>4$ & & \\
Education & 56 & 6.8 \\
None & & \\
Primary/ & 12 & 1.4 \\
Arabic School & 5 & 1.4 \\
Secondary & & \\
Occupation & 71 & 4.1 \\
Housewives & 1 & 16.4 \\
Tailor & 1 & 79.5 \\
Trader & & \\
Booking status & & \\
Booked & 3 & \\
Booked & & \\
Elsewhere & 12 & \\
Unbooked & 58 &
\end{tabular}

Table 2 Associated factors

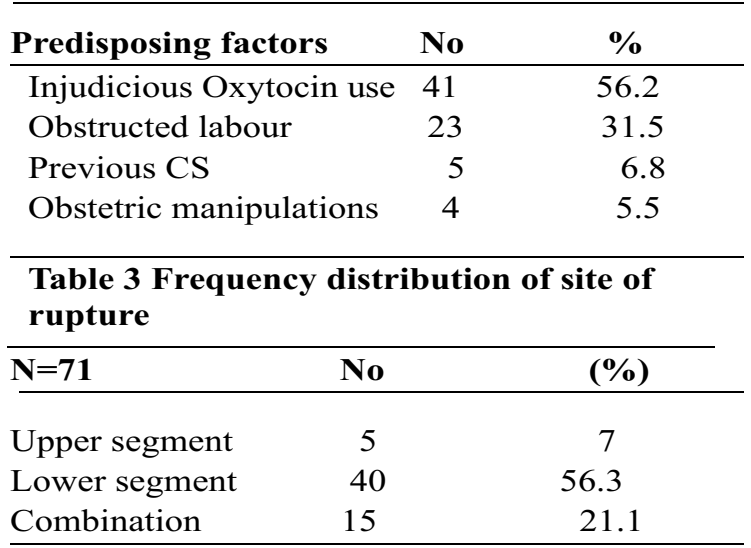

Table 4 Types of Surgical repair

\begin{tabular}{lcc} 
Surgery & No & \% \\
\hline Subtotal hysterectomy & 13 & 18.3 \\
Repair with tubal ligation & 32 & 45.1 \\
Repair without tubal ligation & 26 & 36.6
\end{tabular}

Table 5 complications

\begin{tabular}{lcc}
\hline Complications & No & \% \\
\hline Anaemia & 33 & 44.0 \\
Vesicovaginal fistula & 4 & 6.7 \\
Burst abdomen & 5 & 6.4 \\
Prolonged hospital stay & 20 & 26.7 \\
Faecal fistula & 1 & 1.3 \\
Puerperal sepsis & 7 & 9.3 \\
Mortality & 8 & 10.7 \\
\hline \multicolumn{2}{c}{ c-some have more than one }
\end{tabular}




\section{Discussion}

The principal finding of the study is the incidence of ruptured uterus of 1 in 120 deliveries. This figure is within the range reported in various parts of Nigeria and sub-Saharan Africa ${ }^{4,5,7,89}$. It is higher than the 1 in 273 and 1 in 210 , deliveries reported from Ife and Ilorin but is similar to the figure from Ibadan (1 in 123). Higher rates of 1 in 74 deliveries and 1 in 81 deliveries had been reported from Sokoto, northern Nigeria and Abakaliki in southern Nigeria $^{6,7,10}$. Studies from Malawi and Ethiopia also reported similar figures ${ }^{9,11}$. While the different rates may be reflective of availability and utilisation of Obstetric services in various parts of the country, it is a fact that uterine rupture is definitely a common problem in Nigeria. Low incidence is found in the developed countries ${ }^{12,13}$.

It is noteworthy that majority of the patients (79\%) were unbooked. This is similar to findings in other studies in Nigeria, ${ }^{4,7}$. Lack of antenatal care is associated with increased maternal and foetal morbidity. In this study only $6.8 \%$ of the patients had formal education up to secondary level and none of the husbands is in the professional cadre or member of the political class. The role of formal education in maternal health has been well described by Harrison and colleagues in Zaria Maternity Survey ${ }^{2,3}$.

Uterine rupture was higher in those with parity of 4 and above $(63 \%)$ in this series. This is in contrast to the higher rate among Para 2 in Ibadan ${ }^{10}$. The difference may be due to the obstetric characteristics of the studied population. Higher parity is a known predisposing factor. Also multiparous women are more likely due to their socalled? experience? to delay seeking care.

Majority of the patients (93\%) had rupture of unscarred uterus. This is similar to the findings in Ife but in contrast to those of Singapore and reports from the West where most of the rupture occurred in scarred uterus ${ }^{4,5}$. Over half of the patients who were mainly multiparous had intervention with oxytocin before presentation. Most of the patients had at least one reason why oxytocin was either relatively or absolutely contraindicated. A lot had obstructed labour and had no antenatal care. The use of oxytocin in the patients suggested a defect in the knowledge and practices associated with this potentially dangerous drug among workers in primary health centres. In most of the cases referred, the decision was taken rather too late to salvage the foetuses. Similar to other studies, the majority of patients in our study had complete uterine rupture and the commonest site was the lower uterine segment ${ }^{4,13,15}$.

There is controversy among obstetricians as to the operative procedure of choice for ruptured uterus. The type of surgery embarked upon is mainly dependent on the patient's status, surgeon's experience and the socio-cultural background of the patients $^{14}$. Most patients (45\%) had repair and bilateral tubal ligation, $36 \%$ had repair without tubal ligation and $18.3 \%$ had hysterectomy. This study recorded significantly high rates of repair with or without sterilization. Most Nigerian women want to maintain their reproductive ability ${ }^{4,14}$. However, over two-third of patients lost their reproductive and/or menstrual function in the cases studied. The rest could only reproduce at a greater risk.

The high number of those that had repair may also be a pointer to the fair number of women in the early part of their reproductive career. Ruptured uterus has grave socio-cultural implications, especially in our society where these functions are considered the very essence of womanhood ${ }^{4}$. For a preventable condition, the morbidity and mortality associated with ruptured uterus remains unacceptably high.

In this study, maternal case fatality of $10.7 \%$ recorded is similar the $10.2 \%$ from Malawi but lower than the quoted figures from other studies in Nigeria. These include $17 \%$ in Ife and $38 \%$ in Sokoto $^{4,7,9}$. A good number of maternal deaths were recorded in the post-operative period and complications of overwhelming sepsis and anaemia were mainly responsible. This is similar to the findings from Kaduna in North West Nigeria ${ }^{12,15}$. Regular supply of drugs and blood availability is a serious challenge in the post-operative period in our set up. Foetal mortality is even higher $(86.3 \%)$. This finding is comparable to those recorded in other studies with $92.4 \%$ recorded in Ibadan and $92 \%$ in Ilorin $^{5,10}$

The most common complication in this study was anaemia (44\%), then prolonged hospital stay $(26.7 \%)$. This has economic implication on loss of man-hours and availability of hospital beds to those in need. In our hospital and studies done elsewhere, vesicovaginal fistula, post-operative wound infection and sepsis were the other maternal morbidities associated with rupture of the uterus.

The high maternal morbidity, maternal mortality and fetal mortality that follow uterine rupture calls for an integrated effort to prevent its causes. 
Restructuring the health system to ensure seamless communication between tertiary centres and the referring facilities is needed. Good antenatal care, Family planning services, prompt referral of obstructed labor, availability of transportation and capacity building of staff are the essential factors to prevent uterine rupture and to decrease the maternal mortality, foetal mortality and maternal morbidity associated with it.

\section{References}

1. Ande ABA. Uterine rupture In Okpere EE (ed). Clinical Obstetrics 2004 ,University of Benin Press, Benin :241-244.

2. Galadanci HS, Ejembi CL, Iliyasu Z, Alagh B, Umar US.Maternal health in Northern Nigeria: A far cry from the ideal. BJOG, 2007;114(4): 448-452

3. Harrison KA.1997. Maternal mortality in Nigeria. The real issues. Afr. J. Reprod. Health. (1): 7-13

4. Ezechi OC, Mabayoje P, Obiesie LO, Ruptured uterus in South Western Nigeria: a reappraisal: Singapore Med J. 2004; 45(3):113-116.

5. Abiodun P. Aboyeji, Munir-Deen A. Ijaiya, Usman R. Yahaya, Ruptured uterus; A Study of 100 consecutive cases in Ilorin,Nigeria: J. Obstet Gynaecol. Res 2001; 27(6):341-348.

6. Esike CO, Umeora OU, Eze JN, Igberase GO. Ruptured uterus: the unabating obstetric catastrophe in South eastern Nigeria. Arch Gynecol Obstet. 2010

7. Ekele BA, Audu LR, Muyibi S. 2000 Uterine Rupture in Sokoto, Northern Nigeria - Are We Winning? Afr. J. Med. Sci. 29: 191-193

8. Ezegwui H.U, Nwogu-ikojo EE, Trends in uterine rupture in Enugu, Nigeria: J Obstet Gynaecol 2005;25(3):260-262.

9. Philip JA. Ruptured Uterus in Mulanje CCAP Hospital (1974-1982).Trop Doct 1990; 20:175-176.

10. Ogunnowo O, Olayemi O, Aimakhu CO.2003. Uterine rupture. The UCH Experience. West Afr J Med 2003.22: 236-239.

11. Gessessew A, Melese M M. Ruptured uterus-eight year retrospective analysis of causes and management outcome in Adigrat Hospital, Tigray Region, Ethiopia. Ethiop.J.Health Dev.2002;16(3):241-245.

12. Adesiyun AG, Zayyan MS, Ameh CA, Ruptured Uterus in a Tropical Teaching Hospital: Choice of Surgical Treatment versus Maternal Outcome, J Turkish-German Gynecol Assoc, 2008, 9(3):144-148.
13. Ozdemir I, Yucel N, Yucel O, Rupture of the pregnant uterus: a 9-year review: Arch Gynecol Obst. 2005 2125.

14. Lawson JB. Sequelae of Obstructed labour. In: Lawson JB, Stewart DB,eds. Obstetrics and Gynaecology in the Tropics and Developing Countries. London: Arnold; 1967:203-210.

15. Onwuhafua P, Onwuhafua A, Omekara D, Ibrahim R. Ruptured uterus in Kaduna, Nigeria: a six year review. J Obstet Gynaecol 1998; 18(5):419-423. 